\title{
Sustainable cost reductions obtained by using a fourth party logistics provider
}

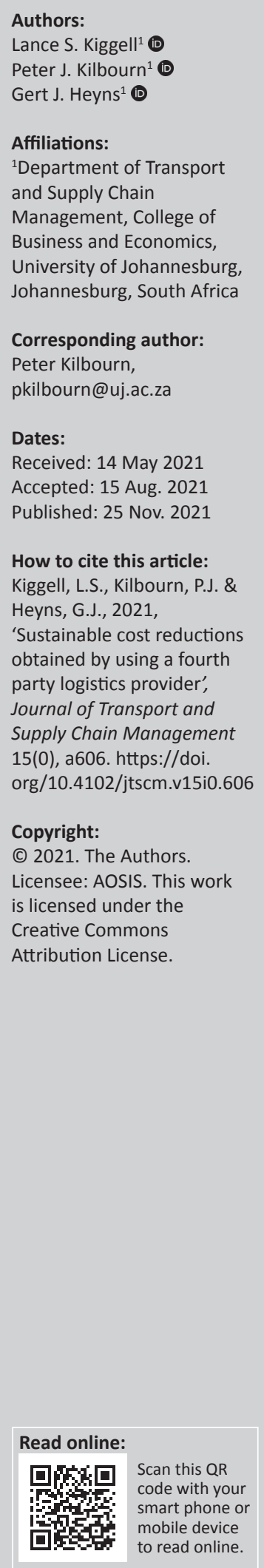

Background: in a rapidly changing global business environment, the outsourcing of logistics activities to fourth party logistics (4PL) service providers is growing in popularity as a strategy for efficiency and customer service improvements.. However, there are very few empirical studies on logistics outsourcing performance. In addition, there is a lack of information on the effectiveness of a 4PL model, especially from a South African perspective.

Objectives: The main purpose of this study was to determine if the use of a 4PL model to manage the courier distribution for a major retailer in South Africa was able to achieve ongoing cost savings for the client.

Method: This research entails a case study of a large non-food retailer in South Africa. Secondary quantitative distribution cost data covering a 10-year period was analysed, using a time series method. The findings were verified through semi-structured interviews of key personnel involved in the implementation and management of the outsourcing contract.

Results: The outsourcing of courier distribution management resulted in the targeted cost savings for the client organisation to be exceeded. Cost savings were consistent over a 10-year period.

Conclusion: The findings of this study supports the theory that the outsourcing of logistics functions can result in sustainable cost savings for clients if done properly. It adds to the limited body of independent evidence that exists on the matter of sustainable results obtained from 4PL outsourcing agreements.

Keywords: fourth party logistics; logistics outsourcing; contract management; courier distribution; supply chain management; sustainable cost savings.

\section{Introduction}

The outsourcing of logistics functions or elements thereof has become a popular strategy aimed at making organisations more efficient and effective. Logistics outsourcing is an arrangement whereby a client organisation contracts a logistics service provider (LSP) to perform services 'that could be, or have been, provided in-house' (Lynch 2000:2). The norm is that non-core services are outsourced (Frazelle 2018; Mkansi, McLennan \& De Villiers 2019). One of the main reasons for the outsourcing of logistics activities is the need to reduce cost (Baluch 2005:139; Godsmark \& Richard 2020:51; Rushton, Croucher \& Baker 2016:651). Other reasons include: the need to improve logistics performance, to access industry knowledge and best practice, to reduce asset capital, to release working capital, to utilise new technology, to transfer complexity, to obtain increased flexibility and scalability as well as to reduce risk (Frazelle 2018; Godsmark \& Richard 2020:50-55).

Cost reductions as an achievable goal of logistics outsourcing has been confirmed by various studies (Baluch 2005:139; Capgemini \& Langley 2017; Godsmark \& Richard 2020). A question which largely remains though, is whether such cost reductions achieved through the outsourcing of logistics activities are sustainable. Clients of outsourcing providers should ideally be able to maintain or further capitalise on benefits accruing from outsourcing agreements over the longterm, also after such an agreement has been terminated. The LSPs will frequently advertise their ability to provide sustainable cost savings for clients. However, they tend to rate their own capabilities and achievements higher than the client organisations (Langley 2016).

Logistics outsourcing appears to be a growing industry. A significant study informing industry of logistics outsourcing trends in industry is the Annual Third-party Logistics Study by Capgemini and Langley (2017) who gathered data from North and South America, Asia and Europe. The 
study showed that organisations have consistently reported an increase in the use of outsourced logistics services over the last 20 years. It also reported that $58 \%$ of the shippers increased their use of outsourced services down from $73 \%$ reported in the previous report. The activity most commonly outsourced is domestic and international transportation (Capgemini \& Langley 2017). Confirmation exists of LSPs achieving the required outcomes for clients. According to the 2017 Thirdparty Logistics Study, 75\% of those who use logistics services and $93 \%$ of Third Party Logistics (3PL) organisations indicate the use of 3PL services that had contributed to overall logistics cost reductions, while $86 \%$ of the shippers and $98 \%$ of the 3PL organisations indicate that the use of 3PLs had contributed to improved customer service (Capgemini \& Langley 2017:4). This finding is supported by a number of older studies also (Bowersox 1990:2; Deepen 2007:2; Elmuti 2003:36; Stock \& Lambert 2001:359; Waugh \& Luke 2011:337).

From a South African perspective, Waugh and Luke (2011:348), undertook local research and found that companies had multiple reasons for outsourcing. Figure 1 illustrates the findings from the study, in which the three main reasons provided include: a focus on core competencies; the geographical coverage; and improvement of the customer service.

Apart from 3PL providers, there are various categories of LSPs. A First Party Logistics (1PL) is regarded as an organisation that provides its own logistics using its own assets. A Second Party Logistics (2PL) provider is an organisation providing physical logistics operations (mostly transport) as a service to clients. The Third Party Logistics (3PL) provider normally takes charge of a part of a client's supply chain and provides more services than only physical execution, including planning and relationship management with clients and suppliers of the client (Tlaty \& Moutmihi 2015). One category of LSPs which is gaining popularity is the Fourth Party Logistics provider (4PL) (Godsmark \& Richards 2020:16). The term 4PL, was first identified in 1996, when Accenture (then Andersen Consulting) registered this term as a trademark (Gattorna 2003:482). It was defined as 'an integrator that assembles the resources, capabilities, and

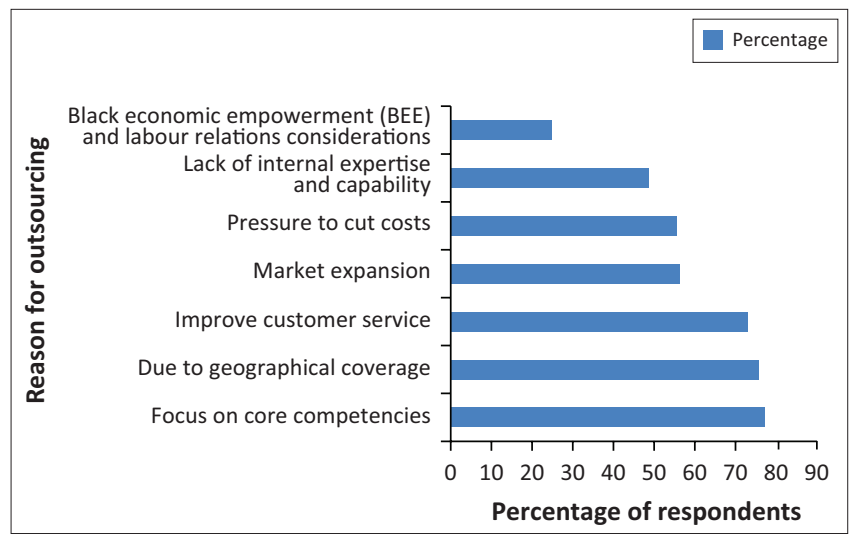

Source: Waugh, B. \& Luke, R., 2011, 'Logistics outsourcing by manufacturers in SA', The Journal of Transport and Supply Chain Management 5(1), 337-360. https://doi. org/10.4102/jtscm.v5i1.81 FIGURE 1: Percentage of respondents technology of its own organisation and other organisations to design, build and run comprehensive supply chain solutions' (Gattorna 2003:482). A 4PL model entails that an outsourced service provider neutrally manages the entire logistics process on behalf of a client (Mkansi et al. 2019; eds. Sahay \& Sahay 2006). Normally, the 4 PL is a non-asset based operator that provides value-addition through its ability to leverage the execution ability of various subcontractors using its own staff expertise and advanced information systems (Godsmark \& Richards 2020; Mkansi et al. 2019). The 4PL is also considered a high value-added provider who serves to find the best possible solution for a client by subcontracting to other LSPs who have the necessary expertise and capability (Mkansi et al. 2019).

In literature there is ample evidence of the introduction of a logistics intermediary resulting in cost savings, improvements in quality, customer service, and other benefits (Capgemini \& Langley 2017; Deepen 2007:2; Hsiao et al. 2010:395; Wallenberg 2009:75). However, very few empirical studies exists in relation to logistics outsourcing performance (Deepen et al. 2008:76). In addition, no research could be found on the effectiveness of a 4PL model, especially from the South African perspective. Furthermore, no study could be found making reference to the sustainability of cost savings achieved from outsourcing agreements.

The objective of this study was to determine if the use of a 4PL service provider to manage the courier distribution for a major retailer in South Africa, was able to achieve ongoing cost savings for the client. This study specifically looks at the retailers decision to migrate from managing multiple service providers in a 3PL model, to appointing a single 4PL to manage all of their courier distribution. Insight into the results of the outsourcing agreements could guide companies in terms of their decision-making and expectations around outsourcing contracts where 4PL service providers are involved. The findings of this study can also assist LSPs in an understanding of the value-addition created by them. Furthermore, the method used to analyse the cost savings over an extended time-period provides a useful example of the type of performance measurement required for strategic outsourcing contracts.

In the following section, a theoretical framework is provided to reflect more deeply on the concept of the 4PL provider and existing studies relevant to the research problem. Thereafter, follows a description of research methodology and results of the study conducted before concluding the article by providing limitations, recommendations and a conclusion.

\section{Theoretical framework}

To create the necessary context for the remainder of this study, this section is dedicated to an explanation of the various levels of outsourcing and potential advantages and disadvantages associated with an outsourcing strategy. 


\section{Levels of outsourcing and potential benefits}

The design of the outsourcing process is the primary decider in the success of the outsourced project. Furthermore, the relationship between the LSP and its customer is of particular importance. This relationship plays a bigger role than the actual extent to which a firm outsources its logistics processes (Deepen 2007:2; Mkansi et al. 2019). Three levels of outsourcing are evident in the literature: tactical, strategic and transformational. The tactical level implies reasons for outsourcing are as a result of specific problems that an organisation is trying to solve, such as reducing operating costs, freeing up internal resources, and addressing inadequate managerial competence or talent (Brown \& Wilson 2005:19-43). On a strategic level, the most common reason for outsourcing is to refocus management staff on the core business functions (Godsmark \& Richards 2020). Other reasons include: gaining access to world-class expertise or to external resources; accelerating the benefits of restructuring; improving customer satisfaction; increasing company flexibility; and sharing in risks (Godsmark \& Richards 2020; Van Weele 2010:164). Strategic outsourcing relationships build long-term value, enabling organisations to work with fewer, best-in-class integrated service providers (Ghodeswar \& Vaidyanathan 2008:25). Transformational outsourcing is commonly used to facilitate rapid organisational change, and to launch new strategies or for restructuring company boundaries (Linder 2004:52). The transitional level enables an organisation to maintain its leadership position and build a sustainable competitive advantage. Transformational outsourcing also addresses issues such as: good governance, maturity of business process knowledge, and the drafting and monitoring of service level agreements (Ghodeswar \& Vaidyanathan 2008:26). The levels of risk associated with strategic and transformational outsourcing are higher than in tactical outsourcing, but these risks are normally shared with the outsourcing partner. The successful implementation of an outsourcing strategy requires prior testing in order to develop risk mitigation plans and high-security levels. It also requires mature project management skills and established business continuity plans (Ghodeswar \& Vaidyanathan 2008:25).

\section{Potential disadvantages of logistics outsourcing}

When considering an outsourcing arrangement, organisations need to factor in potential disadvantages associated with the outsourcing of logistics activities. Various disadvantages have been identified in the literature. The loss of control is one potential disadvantage (Razzaque \& Sheng 1998; Soodyall \& Singh 2013), and could raise an organisation's exposure to liability (Elmuti 2003:3). Increased dependency on the LSP from both a quality and cost perspective is another potential disadvantage. Wentworth (2003:57) reported that firms must use data provided by the LSP to measure the quality of service provided. In addition, Deepen (2007:24) added that when a firm outsources a logistics service, it loses its internal logistics skills required to judge the performance of the external service provider. As a result, it is reliant on the truthful declaration of costs from the LSP unless it is able to introduce control mechanisms which invariably increase transaction costs. Furthermore, insufficient attention to complex issues, such as a formalised outsourcing process, proper cost analysis and a thorough understanding of the core business, can lead to sub-optimal results (McIvor 2000:25-26). Outsourcing can potentially also create a fear of job loss within the workforce (Elmuti 2003:33) and a loss of morale and dedication of the employees (Kujawa 2003:8).

In summary, a detailed analysis of an outsourcing strategy is necessary to understand the pros and cons of each specific option to determine if the strategy will be beneficial for the client. It is also important that once the outsourcing agreement is in place, the client organisation regularly conducts a proper analysis of quantifiable performance results linked to its outsourcing arrangement to determine the feasibility of the project. Gains have to be viewed in the context of potential trade-offs with disadvantages.

\section{Methodology}

This study followed a case study design underpinned by the philosophical approach termed pragmatism, which is defined by the Oxford English Dictionary (2017) as 'an approach that evaluates theories or beliefs in terms of the success of their practical application'. The case study design was appropriate to the study as it used the data accumulated over a defined time period and also different sources of data were used.

This research entailed a case study of one of the largest nonfood retailers in South Africa, a well-established company, who has outsourced the courier distribution part of its operations to a $4 \mathrm{PL}$ service provider. This study is a single case study with an embedded unit of analysis as it represents a typical case (Yin 2014). The lessons learned through this case study were representative of the 4PL outsourcing model. A typical case implies that the particular set of circumstances around the focal entity is similar in relevant characteristics to other cases of the same type (Gomm, Hammersley \& Frost 2000:167). This study is an embedded case study because of the focal company's courier distribution being split based on the different product types distributed, and analyses of each type separately.

The research strategy selected entailed a multi-method study in which both quantitative and qualitative research were conducted. Secondary quantitative distribution data were analysed to identify distribution cost trends. This case study required a time series analysis, in which quantitative product distribution data over the period from 2007 to 2016 was analysed to identify distribution cost trends. Current distribution costs were compared to the costs incurred prior to the appointment of the 4PL organisation. In addition, it investigated other parameters that can be measured through the data available, such as service levels achieved. Qualitative data was collected to support the results of the analysed data by conducting interviews with key personnel within the 
retailer and the appointed 4PL to validate the findings presented.

\section{Quantitative data analysis method}

A time series analysis was conducted on the data collected to extract meaningful statistics from the data as well as to identify other salient characteristics. A time series analysis tracked the performance of a single variable - average cost of distribution per $\mathrm{kg}$ delivered - over an extended period. According to Yin (2014:151), a major strength of case studies is the ability to trace changes over time. This analysis traced events over the identified time period to identify and understand the drivers that impacted on the variable measured.

The following steps were undertaken in the time series analysis:

- established a cost benchmark prior to the implementation of the 4PL model; that is the distribution costs incurred by the 3PL model previously followed by the retailer;

- forecasted the trend in this benchmark over the identified period, based on the premise that the 4PL model and any other cost saving initiatives were not embarked upon, that is continuing with the 3PL model previously followed by the retailer;

- calculated the actual trend in the cost benchmark over the same period;

- compared and quantified the difference between these two measures; and

- identified the factors that contributed to the difference between these two measures, that is comparing the forecasted benchmark trend to the actual cost trend.

The above exercise was carried out for each product type distributed, including, for example, domestic shipments, inter-store merchandise transfers, international, stationery, high value merchandise, point of sale (POS) material and IT equipment. The comparison tracked the trend in the benchmark value (without the 4PL implementation) against the actual value, then quantified and explained the difference. Based on the above steps, the average cost of distribution per $\mathrm{kg}$ delivered was identified as an appropriate metric that formed the starting point of the statistical analysis conducted. Each month, the 4PL submitted a detailed schedule of all deliveries handled in a month, plus the cost per delivery. This information was used by both parties to calculate the monthly average distribution cost per $\mathrm{kg}$. Any material change in this figure was then analysed in more detail to identify the reason(s) for the variance.

The first step in this study's analysis calculated a benchmark cost per $\mathrm{kg}$ prior to the implementation of the 4PL model, and then calculated the anticipated trend in the cost per $\mathrm{kg}$ based on the assumption that the 4PL model was not implemented in 2007. Curve fitting is required to visually identify the trend in the relationship between the data points. Curve fitting involves the empirical determination of a curve or function that approximates a set of data (Merriam-Webster 2017). The construction of this time series involves smoothing in which a smooth function is constructed that approximately fits the data. To perform this, the analysis identified the factors that impacted on this trend, such as the price of fuel, the price of labour, vehicle prices, and general inflation. The result of this was a trend line in the benchmark cost per $\mathrm{kg}$ from 2007 to 2016.

In the second step, the actual cost per $\mathrm{kg}$ was measured for the same period. Then, the benchmark cost per $\mathrm{kg}$ and the actual cost per $\mathrm{kg}$ were compared to calculate the difference between the two values. This comparison was then displayed graphically to visually display the difference between the two values.

Finally, the reasons for this trend were identified in some detail. This required understanding the factors that contributed to the trend in the cost per $\mathrm{kg}$. There were a number of factors to consider, such as the type of product delivered, the specific delivery routes involved, the weight and volume of deliveries undertaken, and the speed of delivery required. A detailed analysis of the distribution data was required to identify the specific drivers that contributed to the change on the cost per $\mathrm{kg}$ over the period identified.

Courier shipments are delivered in accordance with waybills. These are documents issued by a courier providing the necessary details relating to the shipment of a consignment of goods. A waybill will typically include the name and address of the consignor (sender) and consignee (receiver), the required service code, a description of the goods to be consigned, and the weight and dimensions of the goods. Distribution data from 2007 to 2016 was analysed at the waybill level to calculate the specific costs incurred.

These costs were then broken down in a number of ways to measure actual trends. Firstly, costs were analysed based on the different types of products distributed. Secondly, costs were further analysed by service type. Service types indicate the speed at which a delivery takes place to compare, for example, the costs of an overnight service on a route, to the cost of a slower service for the same route. Costs can be broken down further based on specific routes, such as the cost of delivering from Gauteng to Kwazulu Natal, or, even more specifically, from Johannesburg to Durban. The objective of the data analysis was to calculate the following:

- the total amount spent per product category per month over the period identified;

- the volumes delivered per product category per month, measured in kgs;

- the resultant average cost per $\mathrm{kg}$ per product category per month or per quarter; and

- the comparative cost per $\mathrm{kg}$ based on the benchmarks determined prior to the implementation of the 4PL model.

There are many reasons for analysing the data at the waybill level. Firstly, there are no industry-wide accepted definitions of courier services. For example, a shipment sent domestically 
on an economy service could take anywhere from 2 to 5 days, depending on the route and the service agreed between parties. Secondly, different couriers consider different areas as main centres, resulting in different costs and service levels for a specific route.

Another factor which can result in differences in costs is the fuel surcharge. Most South African couriers levy a fluctuating fuel surcharge on top of freight charges as a result of the fuel price that changes monthly. The calculation of this surcharge could be based on the legislated price of petrol calculated monthly, or on an agreed benchmark for the price of diesel, or a combination of the two prices.

A further concept that required inclusion in this analysis is the calculation of chargeable weight or mass. Different methods are used to calculate chargeable weight, including actual weight, or the greater of actual and volumetric weight. Volumetric weight is calculated using a volumetric factor which will also need to be analysed further.

Finally, not all distribution costs are based on chargeable weight. For example, cost can also be based on distance travelled to complete a delivery. This is common for emergency deliveries which require dedicated vehicles to deliver specific shipments. As a result, the best way of measuring distribution costs is to interrogate the actual billing data submitted by the carrier at the waybill level.

\section{Qualitative data analysis}

Four semi-structured interviews were conducted: two with the retailer's logistics executives directly responsible for managing the 4PL relationship; and two with 4PL executives directly responsible for the operations undertaken by the $4 \mathrm{PL}$ organisation over the 10-year period. The interviews were conducted in April 2017, and the participants were selected on the basis of their intimate knowledge of the outsourced functions and the expectations set for the outsourcing agreement. By interviewing both the retailer's staff and staff from the 4PL organisation, the viewpoints of all parties were revealed. The purpose of the semi-structured interviews was to validate findings presented from the data analysis, and to obtain further explanation of these findings. Open-ended questions were used to allow participants to further explain the results presented. The responses to each interview were documented and signed by the respondents to produce reliable, verified data for analysis. A directed content analysis method was used to analyse the data as per Hsieh and Shannon (2005). This approach was deemed appropriate since the findings from the content analysis offered supporting or non-supporting evidence (Hsieh \& Shannon 2005) for the findings of the previously conducted quantitative study.

\section{Ethical considerations}

An agreement with the focal organisation in this case study allowed for access to the necessary secondary data and the availability of participants to be interviewed. The agreement also made provision for confidentiality which required that the name of the organisation not be disclosed in the study. Interview participants signed and returned a letter of consent in line with the protocol of the university where ethical clearance for this research was obtained.

\section{Results}

Firstly, interview information obtained about the purpose and scope of the 4PL outsourcing arrangement for the focal company is presented. These provide the context for the analysis performed in determining if the outsourcing agreement resulted in long-term cost savings for the client organisation. Thereafter, results of the time series analysis of cost savings are reported. The impact of the outsourcing arrangement other than the brief to save costs is also reflected through information obtained from company records and interviews with key staff members.

\section{Scope of the outsourcing arrangement}

In May 2007, after an initial analysis period, the appointed 4PL took over the management of the retailer's courier accounts in five product categories. At the time of implementation, the retailer had accounts with five or six couriers for domestic shipments. Different departments within the retailer had separate agreements with different couriers, each with their own rates. As a result, there were over 40 different account of cost centre combinations with no central oversight or control over courier costs incurred (Interviewee A 2017). With the implementation of the 4PL model, the service provider had the responsibility of consolidating the retailer's express parcel distribution requirements into a single platform, with oversight of all courier transactions into one account.

Based on the initial analysis, the 4PL committed to returning a saving of $25 \%$ in the first year (Interviewees A \& C 2017). The following points were identified in the interviews as reasons for high courier costs being incurred:

- different rates charged by the same service provider on different accounts per department within the retailer;

- unidentified and unmanaged courier costs allocated to different cost centres by different departments, for example railage costs, cartage, consulting fees, general expenses, petty cash expenses;

- no consolidation of shipments going from the same place to the same destination, on the same day, on the same service;

- no mechanism to provide courier cost quotes prior to despatch;

- unauthorised shipments;

- premium service selected for all shipments, without any measure of the actual service received; and

- rate increases approved based on changes in the fuel price, resulting in excessive increases.

The implementation of the single platform provided additional benefits as follows (Interviewees A, B, C \& D 2017): 
- one account with the 4PL for all courier costs, enabling centralised control over all distribution;

- an improved visibility of costs, which in turn assisted with decision-making, corrective actions and improved management and accountability over costs incurred;

- an improved track and trace functioning, in order to provide a more proactive management of shipments en route;

- proof of delivery management, that is improved control over proof of delivery of shipments;

- service level management, measuring the extent to which specified service levels were achieved by carriers appointed to each product category;

- a quoting mechanism, facilitating an approval process prior to sending shipments; and

- an extensive data analysis capability, which also contributed to improved decision-making and forecasting.

\section{Product category index}

When analysing a substantial amount of financial data, it is common to calculate average costs in order to develop cost trends over a period. There is always a risk that too much disparate data is aggregated to determine an average cost that is irrelevant for comparative purposes. For example, adding the cost of airfreight distribution plus road-freight distribution on the same route runs the risk of distorting costs per service type. It is vital that average costs are analysed in more detail to determine the reasons for the trends identified. This study attempted to minimise this risk by separating the data into product categories, and analysing the trends in the data over an extended 10-year period.

The expedited courier distribution was classified into multiple separate 'product categories' based on the type of products moved, including international, domestic, interstore transfers, stationery, high value, POS, re-mail, fashion hotline, information technology equipment, and e-commerce deliveries. Optimisation was handled per product category on a project-by-project basis, starting with the domestic product category. The first step in the process was an analysis of the costs, volumes and service types per product category. The result of the analysis was a benchmark cost per kg for each product category, based on the product mix at the time. The benchmark rate per $\mathrm{kg}$ was the average rate per $\mathrm{kg}$ per product category paid by the retailer to its previous service providers as on May 2007.

The next step was to develop an index per product category, in terms of which the benchmark rate per kg in May 2007 was given a value of 100 points. The monthly average cost of $\mathrm{kg}$ per product category per month was then calculated, based on the following calculation per product category:

$$
\begin{gathered}
\text { Monthly average } \\
\text { cost per } \mathrm{kg}
\end{gathered}=\frac{\begin{array}{l}
\text { Total monthly freight } \\
\text { charge billed }(\text { excl.vat })
\end{array}}{\text { Total chargeableweight }}
$$

The average cost per $\mathrm{kg}$ was converted into a point value, as a percentage of the benchmark rate per $\mathrm{kg}$, using the following formula:

$$
\begin{gathered}
\text { Monthly points } \\
\text { value }
\end{gathered}=\frac{\begin{array}{l}
\text { Monthly averagecost } \\
\text { per } \mathrm{kg}(\text { excl.vat })
\end{array}}{\begin{array}{l}
\text { Benchmark rate } \\
\text { per } \mathrm{kg}(\text { excl.vat })
\end{array}} \times 100
$$

For example, if the benchmark rate per $\mathrm{kg}$ for a specific product category was $\mathrm{R} 5.00$ per $\mathrm{kg}$, and the actual rate per $\mathrm{kg}$ for a specific month was R5.50, the points value for that month would be calculated as R5.50/R5.00x $100=110$, indicating a $10 \%$ increase in the rate per $\mathrm{kg}$ for that product category.

The index had two objectives. Firstly, it was intended to provide a trend line to illustrate the costs incurred over the period analysed. At the same time, the index was intended to respect the confidentiality of the data presented, by not displaying the actual costs incurred. A second index is presented based on a consolidated view of all the product categories analysed.

\section{Anticipated trend line}

The next step was to present a predicted trend line in the rate per $\mathrm{kg}$ per product category. This trend line was based on the assumption that the mix of product delivered within a product category in a month did not change materially from the product mix analysed when calculating the benchmark rate per $\mathrm{kg}$. Any change in one of a number of factors could have a material impact on the average cost per $\mathrm{kg}$. These factors included the following:

- $\quad$ service type (i.e. speed of delivery);

- weight (i.e. actual weight of product shipped);

- size (i.e. volumetric weight of product shipped);

- geographic distribution (i.e. points of despatch and delivery);

- domestic route mix (e.g. local deliveries within main centres, regional deliveries, rural deliveries);

- international route mix (e.g. shipment of merchandise samples from new suppliers identified in new countries);

- product type (i.e. type of items shipped);

- seasonality (e.g. distribution of promotional material based on seasonal campaigns);

- freight rates charged by service provider.

The anticipated trend line was based on the assumption that the product mix within a product category does not change materially, and identifies the impact of cost drivers that result in the average rate per $\mathrm{kg}$ changing over time. To do this, the analysis identified the factors that impacted on this trend, such as the price of fuel, the price of labour, vehicle prices, and general inflation. The final result of this was a trend line in the average monthly benchmark cost per $\mathrm{kg}$ from 2007 to 2016 .

The standard courier transportation rate includes a minimum charge, billed for an inclusive shipment weight, 
plus an additional rate per $\mathrm{kg}$ above the minimum weight, for example R50 for $5 \mathrm{kgs}+\mathrm{R} 5$ per $\mathrm{kg}$ thereafter. This is a basic rate structure for a delivery between main centres, for example Johannesburg to Cape Town. In addition, an additional charge is added where the point of despatch or delivery is outside of the main area. Changes to the rates charged by the $4 \mathrm{PL}$ to the retailer per product category were based on the four components presented in Table 1.

The percentage contribution of each of the above components to the total cost was jointly agreed between the retailer and the 4PL. Subject to specific discussions held regarding optimisation initiatives on product categories, negotiations regarding any changes in the rates based on the above components were generally held on an annual basis. This included any adjustments to the percentage contribution of each component to the total cost. Further arrangements between the two parties entailed the following:

- Change in vehicle costs was based on a number of factors, including changes in rates from airlines for airfreight shipments, changes in line haul costs, and changes in rates agreed with carriers, based on factors not included in the other components identified.

- Changes in the cost of labour were based on increases agreed by the Road Freight Association, within the National Industrial Council.

- Changes in administrative costs were based on the consumer price index (CPI), published by Statistics South Africa, the national statistics service of South Africa, as an economic indicator of inflation.

Fuel was managed differently. A fuel surcharge percentage was calculated per product category, based on an agreed base percentage and period, and fluctuated monthly, based on diesel price each month, specifically the Reef wholesale price of standard grade diesel, containing 500 ppm (parts per million) sulphur.

Ideally, the resultant trend line based on the above four components would entail three components increasing annually, with the fuel component increasing monthly. However, owing to the fact that each product category followed a different timeline, with increases negotiated at different times of the year, the trend line submitted follows monthly increases for all four components. Secondly, based on the agreement between the retailer and its $4 \mathrm{PL}$, the trend line used the CPI as an overall indicator of inflation in vehicle costs. Any departure from this needed to be motivated separately by the carriers.

\begin{tabular}{llc} 
TABLE 1: Rate card cost drivers. & Example (\%) \\
\hline Component & Comment & 35 \\
\hline Vehicle costs & $\begin{array}{l}\text { Including airline/line haul costs/carrier rate } \\
\text { changes negotiated }\end{array}$ & 40 \\
Labour related costs & National Bargaining Council & 25 \\
Administrative costs & Consumer Price Index & - \\
\hline Fuel & Reef Diesel 500 ppm wholesale price & \\
\hline
\end{tabular}

PPM, parts per million.
Figure 2 shows the monthly changes in inflation and in the price of diesel (500 ppm) from May 2007 to December 2016 -a period covering 116 months. This graph clearly illustrates how widely the price of fuel fluctuated when compared to inflation. In contrast, inflation shows a more stable average increase of $0.667 \%$ per month over the 116 months included in the period analysed.

The next question to be addressed was how much fuel contributed to the cost of distribution, and ultimately to the rates charged by carriers and by the $4 \mathrm{PL}$ as a result. According to the 4PL, this figure fluctuated significantly between carriers, ranging from $7.8 \%$ to $38 \%$. As a result, it is not possible to do a direct comparison between two couriers, based on their rates alone. A proper cost comparison requires a detailed analysis of the complete billing structure of each courier in order to calculate the total freight charge levied on a waybill. Only then can a price comparison between couriers be performed. In addition, an investigation into the courier rate cards revealed that a number of carriers adjusted the fuel surcharge on an annual basis, while the balance adjusted the fuel surcharge on a monthly basis (normally on the first Wednesday of every month) in line with the changes in the fuel price.

The trend line presented in Figure 3 displays the transport index graphically, based on fuel contributing $32 \%$ to the cost of distribution. This is the latest value applied in the pricing model followed by the 4PL for the retailer's distribution over the period analysed.

The total inflation from May 2007 to December 2016 was 77.4\%. Notably, despite the fluctuations in the price of diesel in the same period, the increase in the price of diesel over the same period was very similar, at $78.0 \%$. The resultant increase expected in transport costs was calculated as $77.6 \%$ based on fuel contributing $32 \%$ to overall distribution costs. Based on this index, any item costing R10.00 in May 2007 should cost R17.76 in December 2016. Similarly, any transportation charge of R10.00 in May 2007 should also cost R17.76 in December 2016.

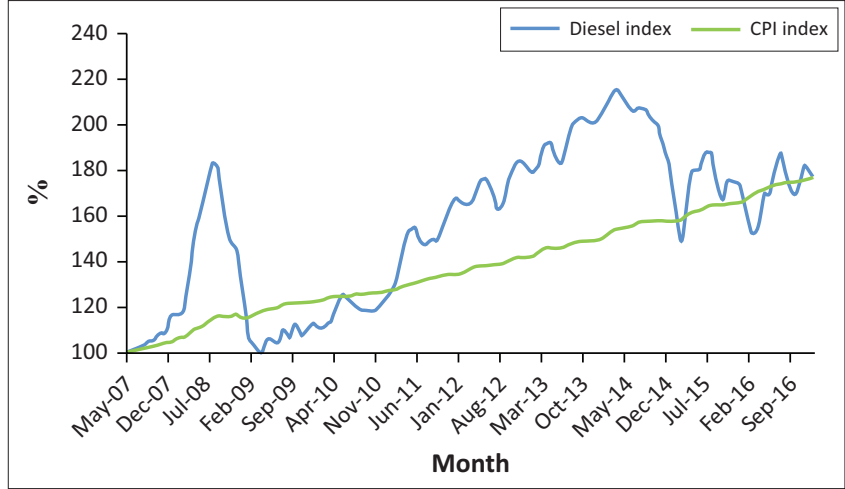

Source: Adapted from Automobile Association of South Africa, 2017, Fuel pricing, viewed 06 April 2017, from https://www.aa.co.za/on-the-road/calculator-tools/fuel-pricing/\&dieselyear=2011.pdf. and Statistics South Africa, 2017, Consumer Price Index, viewed 08 April 2017, from http://www.statssa.gov.za/publications/P0141/CPIHistory.pdf.

FIGURE 2: Trend in the price of diesel, and inflation. 


\section{Consolidated index}

A second index was developed for this analysis, based on a consolidated view of the average cost per $\mathrm{kg}$ using the distribution data provided by the $4 \mathrm{PL}$ organisation. This index combines the benchmark average cost per $\mathrm{kg}$ of each product category, based on the percentage of chargeable weight that each product category contributes to the monthly total. For example, in May 2007, the contribution of each product category to total chargeable weight is presented in Table 2 .

In the first month of this analysis, May 2007, the consolidated benchmark average cost per $\mathrm{kg}$ was identified as the base value of 100 . This value was then adjusted per month based on two factors:

- the transport index as calculated; and

- the monthly contribution of each product category to total chargeable weight.

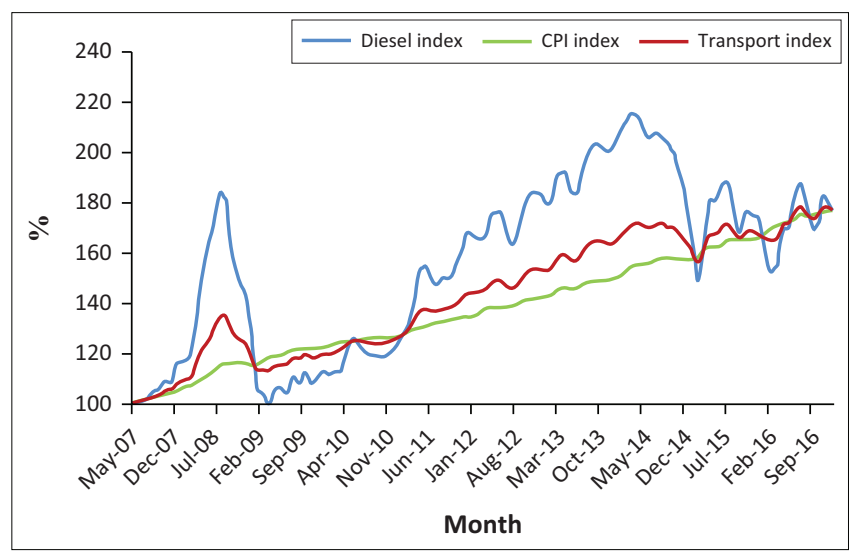

Source: Adapted from Automobile Association of South Africa, 2017, Fuel pricing, viewed 06 April 2017, from https://www.aa.co.za/on-the-road/calculator-tools/fuel-pricing/\&dieselyear=2011.pdf. and Statistics South Africa, 2017, Consumer Price Index, viewed 08 April 2017, from http://www.statssa.gov.za/publications/P0141/CPIHistory.pdf.

FIGURE 3: Transport index trend line.

\section{Transportation rates}

The next step was to merge the findings presented above to provide a consolidated overview of the retailer's total expedite distribution for the period May 2007 to December 2016. Figure 4 displays the total monthly volumes distributed on this network for the period analysed. The graph illustrates the cyclical trend that was common in the retail industry each year, with the highest monthly volumes distributed towards the end of the year, normally each November, and the lowest monthly volumes each January. The decline in volumes from 2013 onwards occurred as a result of the restructuring of different products sent on the courier network.

Figure 5 summarises the monthly volumes to present the total volumes distributed per year using the expedite services, showing the impact of this restructuring more clearly.

Figure 6 identifies the contribution of each product category to the total volume managed on the expedite platform. In the period analysed, the POS product category accounted for $61 \%$ of the total volume, by far the biggest contributor to the total volumes, with the next biggest product category, fashion hotline, only contributing $12 \%$. As a result, the impact of POS has an exaggerated impact when looking at total volumes.

TABLE 2: Contribution of each product category to total chargeable weight May 2007.

\begin{tabular}{lc}
\hline Product category & Percentage of total chargeable weight May 2007 (\%) \\
\hline Cross border & 3.34 \\
Domestic & 23.34 \\
Fashion hotline & 56.53 \\
High value & 9.88 \\
International & 6.91 \\
\hline Total & $\mathbf{1 0 0 . 0 0}$ \\
\hline
\end{tabular}

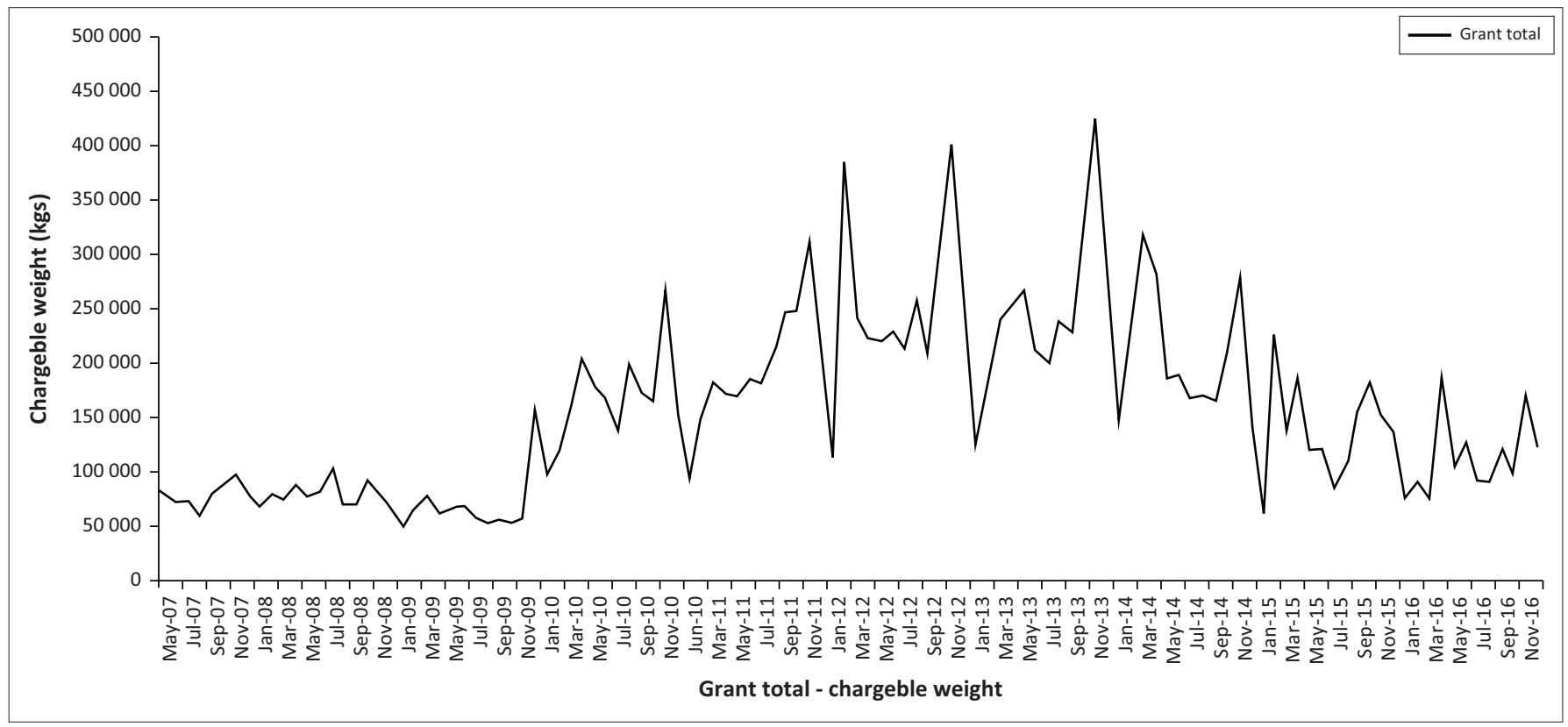

FIGURE 4: Total monthly volumes - May 2007 to December 2016. 
Figure 7 presents a consolidated benchmark index based on the monthly contribution of each product category to the total chargeable weight distributed on the express parcel services. In the first month, May 2007, the benchmark average cost of $\mathrm{kg}$ was identified as the base value of 100 . This graph shows the trend in the total benchmark average cost per $\mathrm{kg}$ for the period analysed. The dramatic decline in the benchmark index in December 2009 was because of the takeon of the POS distribution in that month. As a result of the higher volumes and different service types in this product category, the average cost per $\mathrm{kg}$ was lower for POS than the previous average calculated.

The fluctuations illustrated in this graph occurred as a result of the changing contribution that each product category made to the total. The high benchmark values in January 2013, 2014, 2015 and 2016 resulted from the fact that POS volumes are at their lowest each January. In addition, the increase in the benchmark index from August 2014 was primarily because of the decrease in POS volumes.

Figure 8 provides a comparison of the trend in the benchmark index, to the trend in the actual index. As mentioned, in the first month, May 2007, the benchmark average cost of kg was identified as the base value of 100 . In the same month, the actual average cost per $\mathrm{kg}$ was calculated at an index value of

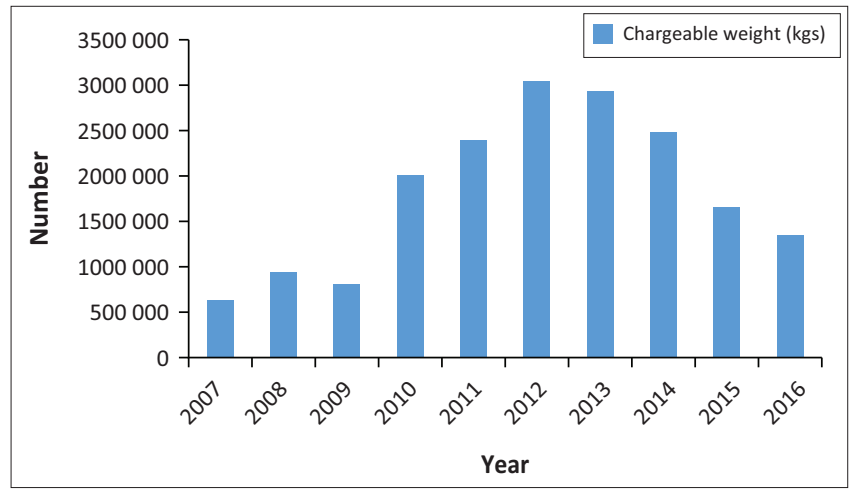

FIGURE 5: Total annual volumes - May 2007 to December 2016.
74.53 , indicating that an immediate saving of $25.47 \%$ was achieved in the first month. As illustrated in Figure 8, the actual index is consistently lower than the benchmark index for the entire period analysed, indicating that ongoing savings were achieved during this time. Based on interviews conducted to verify these findings, it was confirmed that the $4 \mathrm{PL}$ committed to achieving a saving of $25 \%$ on the original product categories taken on. The use of a cheaper economy service as a default was only identified for the domestic product category. For the other product categories, the service or services originally available prior to the implementation of the 4PL were retained, subject to the implementation of an authorisation process to ensure that the use of faster, more expensive service types was properly authorised.

While some of these developments would have taken time to have a material impact on costs, others had an immediate effect. The following three reasons are proposed as major contributors to the immediate savings achieved:

- there is a high probability that some of the previous service providers were making excessive profits because of the lack of a group oversight of rates and increases;

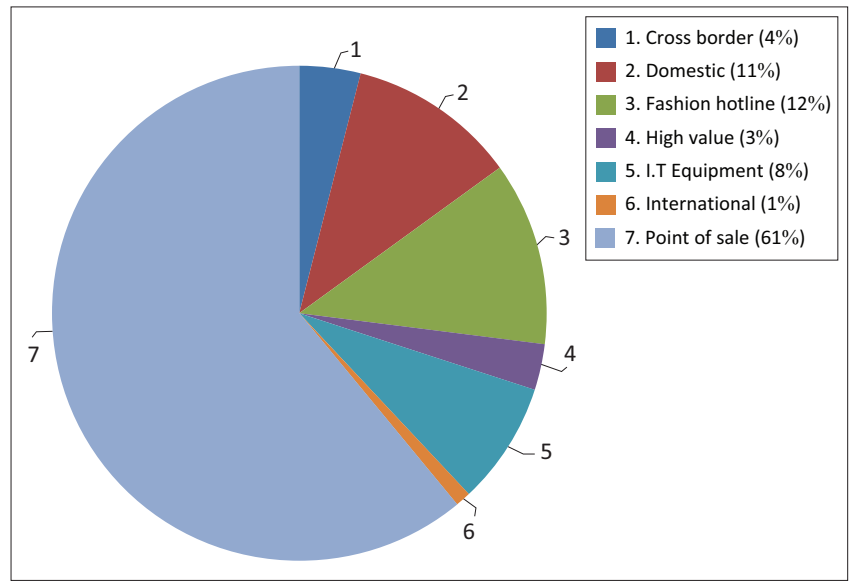

FIGURE 6: Contribution to total volumes of each product category.

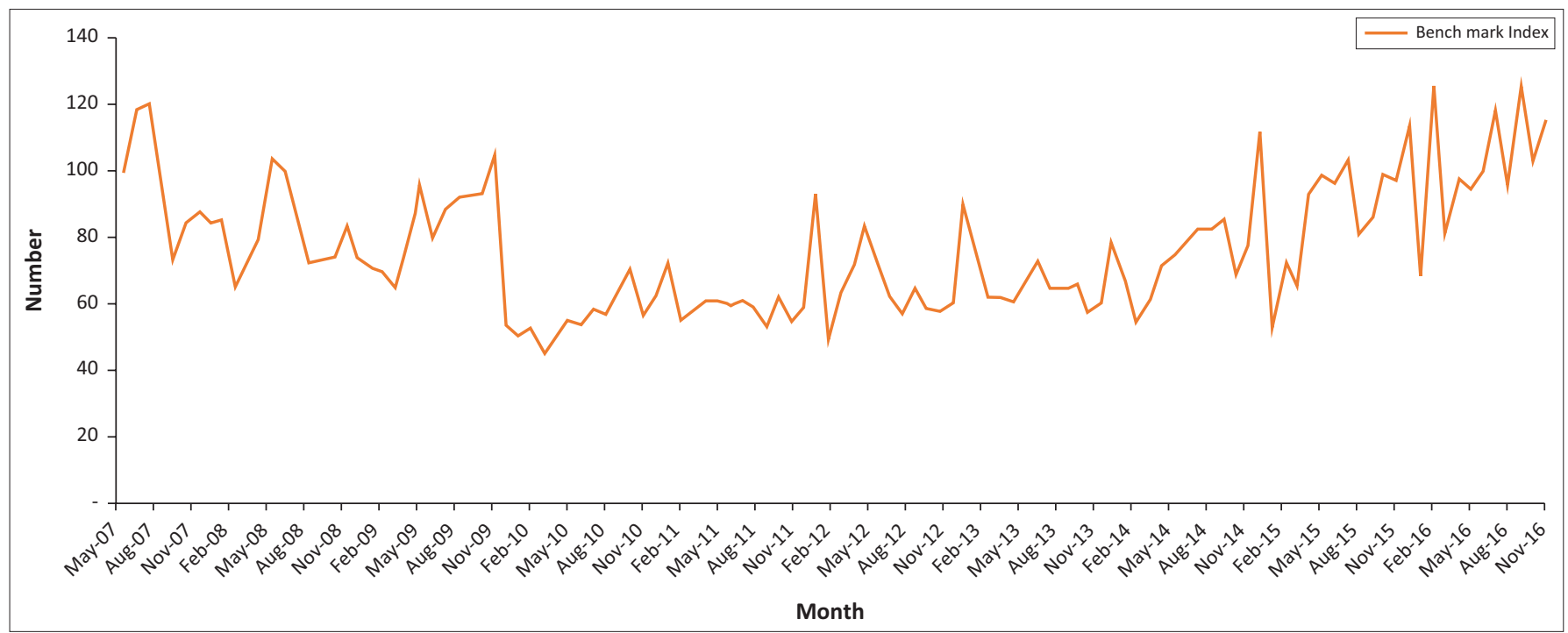

FIGURE 7: Consolidated benchmark index. 


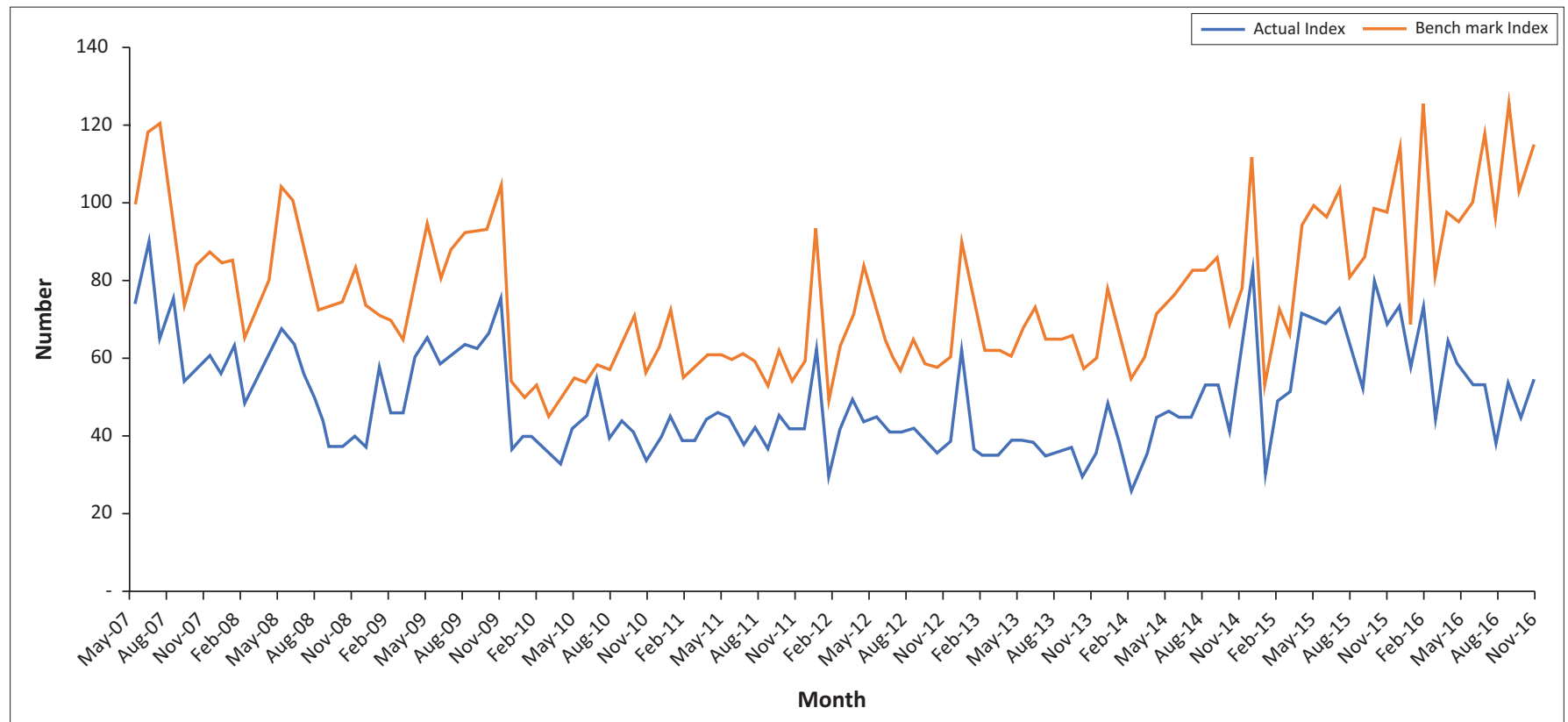

FIGURE 8: Consolidated benchmark index compared to consolidated actual index.

- for the domestic product category, a downgrade of services would have contributed to a reduction in costs; and

- restructuring of rates to more market-related prices, based on the group buying power of the 4PL would also have made a contribution.

The research specifically aimed to identify whether the use of a 4PL outsourcing partner resulted in ongoing savings to the retailer. In other words, this research needs to identify if further savings were achieved above the initial 25\% committed to by the 4PL. As a result, the next step in this analysis required adjusting the benchmark index down by $25 \%$ in order to identify whether further 'ongoing' savings were achieved, in excess of the $25 \%$. Figure 9 presents a revised benchmark index compared to the consolidated actual index.

Where the actual index, (identified by the blue line) is below the revised benchmark index (identified by the yellow line), savings above $25 \%$ were reported in that month. In 97 out of 116 of the periods analysed, savings of over $25 \%$ were achieved. Figure 10 shows the difference between these two lines. In summary, an additional 13.6\% savings were reported, with only 19 months of the 116-reporting a saving of less than $25 \%$. This result clearly confirms the finding that the 4PL model was able to achieve ongoing savings over an extended contract period.

\section{Discussion}

The key findings of this study can be summarised as follows:

- Significant cost savings over the long-term was achieved by the client of a 4PL logistics outsourcing contract.

- The outsourcing arrangement resulted in various sustainable process improvements for the 4PL client organisation.
A carefully comprehensive consolidated index was presented which attempted to verify the savings achieved by the focal company over a 10-year period through the implementation of a 4PL outsourcing model for their courier distribution. This index confirms that the model is able to achieve the initial savings forecast throughout the period analysed. The index was revised to identify if further, 'ongoing', savings can be achieved. For both indices, the trends are displayed graphically to visually identify the savings, while still retaining the confidentiality of the information provided.

The findings of this study support the theory that the outsourcing of logistics functions can result in cost savings for clients if done properly (Baluch 2005; Mkansi et al. 2019). The findings also verify that these cost savings can be sustainable over a long time-period. This confirms the opinion of Christopher (2011) that a 4PL arrangement works best as a long-term one and gains arising from such an agreement should therefore also be of long-term nature. This finding adds to the limited body of independent evidence on the matter of sustainable results $4 \mathrm{PL}$ obtained from $4 \mathrm{PL}$ outsourcing agreements.

It is apparent from the analysis that material savings are generated on all of the product categories managed by the 4PL. Only the domestic product category displays a change in the selection of service types used when a cheaper economy service is implemented as the default service when sending shipments. For all other product categories, a review of lead times selected confirmed that the service types per product category did not change. As a result, these savings are not achieved through the use of a slower, cheaper service. This finding is important in the context of considering the benefits gained from the outsourcing arrangement in a broader context. One of the most fundamental trade-offs in logistics is between cost and customer service (Stock \& Lambert 2001:107). One of the essential requirements of an 


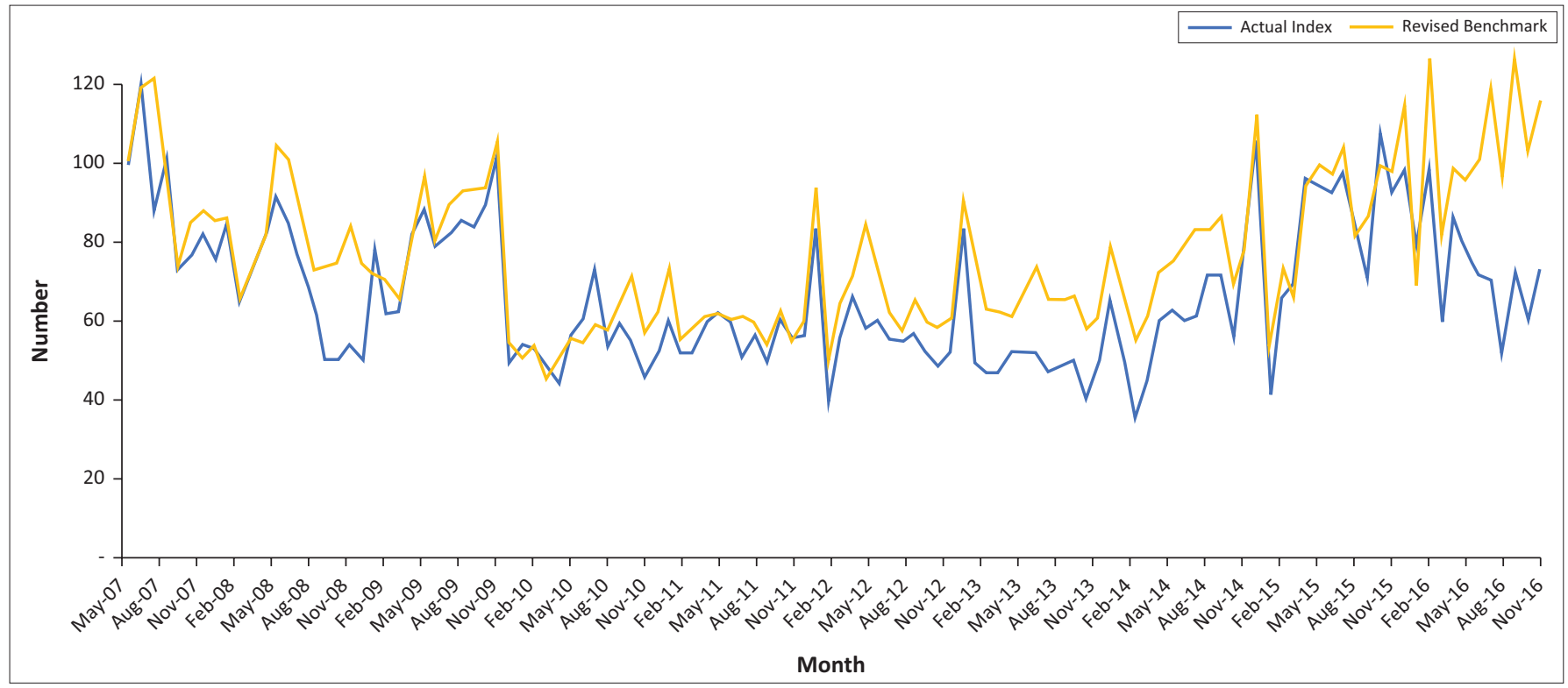

FIGURE 9: Revised benchmark index compared to consolidated actual index.

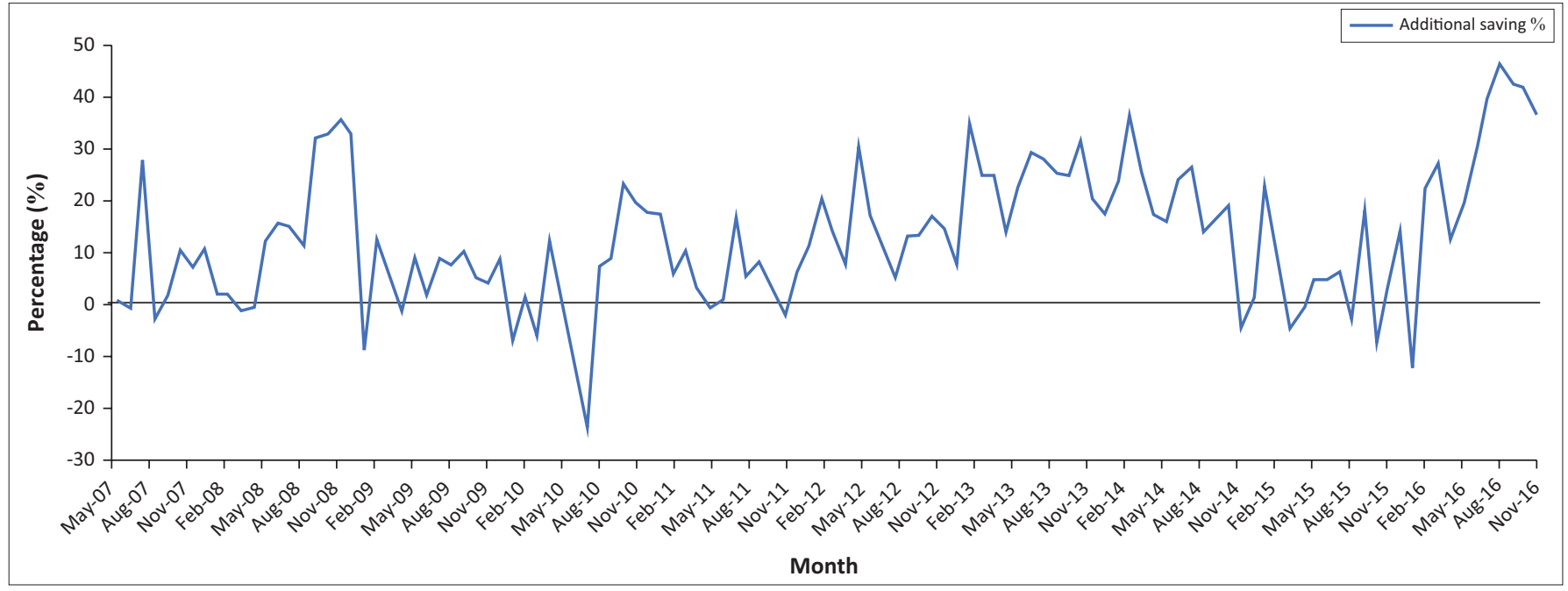

FIGURE 10: Additional savings.

improvement in profitability is to ensure that any reduction in logistics costs does not negatively affect customer service levels and therefore revenue, to the point where costs gains are exceeded (Mkansi et al. 2019). Results from this study suggest that the latter requirement was fulfilled in the outsourcing arrangement analysed.

\section{Limitations of the study}

A limitation was identified within the benchmarking exercise required to calculate the costs of distribution prior to the appointment of the 4PL. To identify whether savings were achieved, it was necessary to determine costs prior to implementation of the new model. This exercise did not illustrate the cost trend over this time period, but only provides a benchmark at a specific point in time.

The second limitation of this study is that it focused only on the express parcel market, and did not consider total distribution. The retail company in question specifically manages, expedites and bulk distributes separately, with different models for each. Owing to the fact that this study focused specifically on 4PL, it did not evaluate the 3PL model used for bulk distribution. Therefore, further studies could explore the potential use of a 4PL model for bulk merchandise distribution of the case company.

\section{Recommendations}

Potential users of 4PL service providers to outsource some or a variety of logistics functions, should note that significant long-term cost savings are possible. It is also possible that these cost savings are not achieved at the cost of customer service levels or cost increases in other related areas. Such a result will imply sub-optimisation and can be prevented by considering total cost and service trade-offs when developing and measuring the effectiveness of outsourcing contracts. To this end, it is recommended that relevant process improvement performance targets are included in the contract together with cost saving targets. It is advisable 
that a comprehensive total cost analysis is done periodically to measure results against clearly set objectives. The time series cost analysis conducted in this study serves as a useful example of how cost savings can be analysed and interpreted.

The improved visibility of the distribution handled within the $4 \mathrm{PL}$ platform provided the retailer with the opportunity to restructure the expedite distribution, and to make use of the platform through its own national transport operations. This occurred for a number of product categories identified. The cost saving realised as a result of this could be argued to have occurred as a result of the 4PL strategy. This saving was not included in this study as it could also be argued to address a different research question, namely one comparing a 3PL strategy to a 4PL strategy. Further research on the savings realised by restructuring the retailer's distribution and moving this distribution into its national transport operations would provide a view of the total savings achieved on both platforms.

\section{Conclusion}

The objective of this study, as identified in the Introduction, was to determine if the use of a 4PL service provider to manage the courier distribution for a major retailer was able to achieve ongoing cost savings for the client. This study specifically looked at the retailers decision to migrate from managing multiple service providers in a 3PL model, to appointing a single 4PL to manage all of their courier distribution. The results of this study suggest that the client organisation was able to achieve significant immediate and ongoing cost savings through the 4PL outsourcing project. The findings of this study supports the theory that the outsourcing of logistics functions can result in sustainable cost savings for clients if done properly. This finding adds to the limited body of independent evidence that exists on the matter of sustainable results obtained from 4 PL outsourcing agreements. For accuracy purposes, the study followed a comprehensive approach in conducting a long-term analysis of cost savings relevant to the outsourcing term. Product cost data was separated in product categories, and data trends were analysed over an extended 10-year time period. Breaking down the distribution into product categories, and analysing the data at the waybill level was able to identify clear cost performance over an extended period. This approach can serve as a useful guideline for others attempting to determine the cost benefits of an outsourcing project.

\section{Acknowledgements Competing interests}

The authors declare that they have no financial or personal relationship(s) that may have inappropriately influenced them in writing this article.

\section{Authors' contributions}

L.S.K. was the principal researcher for this article, whilst P.J.K. and G.J.H. were the supervisors of the study.

\section{Funding information}

The authors received no financial support for the research, authorship, and/or publication of this article.

\section{Data availability}

The data that support the findings of this study are available on request from the author, L.S.K. The data are not publicly available because of restrictions (their containing information that could compromise the privacy of research participants and the case organisation).

\section{Disclaimer}

The views and opinions expressed in this research article are those of the authors and do not necessarily reflect the official policy or position of any affiliated agency of the authors.

\section{References}

Automobile Association of South Africa, 2017, Fuel pricing, viewed 06 April 2017, from https://www.aa.co.za/on-the-road/calculator-tools/fuel-pricing/\&dieselyear=2011.pdf.

Baluch, I., 2005, Transport logistics: Past, present and predictions, Winning Books, Dubai.

Bowersox, D.J., 1990, 'The strategic benefits of logistics alliances', Harvard Business Review July - August, 36-47.

Brown, D. \& Wilson, S., 2005, The black book of outsourcing - How to manage the changes, challenges, and opportunities, Wiley, Hoboken, NJ.

Capgemini \& Langley Jr, C.J., 2017, Third-party logistics study. The state of logistics outsourcing: Results and findings of the 21st annual study, viewed 02 April 2017, from https://www.capgemini.com/news/2017-global-state-oflogistics-outsourcing-study-reveals-evolving-role-of-shippers-and/.pdf.

Christopher, M., 2011, Logistics and supply chain management, 4th edn., Pearson Education, London.

Deepen, J.M., 2007, Logistics outsourcing relationships, measurements, antecedents, and effects of logistics outsourcing performance, Springer Science and Business Media, Heidelberg.

Deepen, J.M., Goldsby, T.J., Knemeyer, A.M. \& Wallenburg, C.M., 2008, 'Beyond expectations: An examination of logistics outsourcing goal achievement and goal exceedance', Journal of Business Logistics 29(2), 75-105. https://doi. org/10.1002/j.2158-1592.2008.tb00088.x

Elmuti, D., 2003, 'The perceived impact of outsourcing on organizational performance', American Journal of Business 18(2), 33-41. https://doi.org/10.1108/1935518120 0300010

Frazelle, E.H., 2018, Supply chain strategy, second edition: Unleash the power of business integration to maximize financial, service, and operations performance, McGraw-Hill Education, New York, NY.

Gattorna, J.L., 2003, Gower handbook of supply chain management, 5th edn., Gower Publishing, Aldershot.

Ghodeswar, B. \& Vaidyanathan J., 2008, 'Business process outsourcing: An approach to gain access to world-class capabilities', Business process Management Journal 14(1), 23-38. https://doi.org/10.1108/14637150810849382

Godsmark, J. \& Richards, G., 2020, The logistics outsourcing handbook: A step-by-step guide from strategy through to implementation, Kogan Page, London.

Gomm, R., Hammersley, M. \& Frost, P., 2000, Case study method, Sage, London.

Hsiao, H.L, Van Der Vorst, J.G.A.J., Kemp, R.G.M. \& Omta, S.W.F., 2010, 'Developing a decision-making framework for levels of logistics outsourcing in food supply chain networks', International Journal of Physical Distribution and Logistics Management 40(5), 395-414. https://doi.org/10.1108/09600031011052840

Hsieh, H.F. \& Shannon, S.E., 2005, 'Three approaches to qualitative content analysis', Qualitative Health Research 15(9), 1277-1288. https://doi.org/10.1177/104973 2305276687

Kujawa, B., 2003, 'An investigation into logistics outsourcing practices, trends and issues within the manufacturing sector in South Africa', PhD thesis, Dept. of Transport and Supply Chain Management, Rand Afrikaans University.

Langley, C., 2016, Third-party logistics study - The state of logistics outsourcing, viewed 16 June 2019, from https://www.3plstudy.com/downloads/ 2016+3PL+Report.

Linder, J.C., 2004, 'Transformational outsourcing', MIT Sloan Management Review (Winter 2004) 45(2), 52-58. 
Lynch, C.F., 2000, Logistics outsourcing: A management guide, Council of Logistics Management, Oak Brook, IL.

Mclvor, R., 2000, 'A practical framework for understanding the outsourcing process', Supply Chain Management: An International Journal 5(1), 22-36. https://doi. org/10.1108/13598540010312945

Merriam-Webster Dictionary Online, 2017, Curve fitting, viewed 10 April 2017, from https//www.merriam-webster.com/dictionary.

Mkansi, M., Mclennan, N.K. \& De Villiers, G., 2019, Contemporary issues in operations and supply chain management, Van Schaik Publishers, Pretoria.

Oxford English Dictionary Online, 2017, Pragmatism, Oxford University Press, viewed 08 April 2017, from https://en.oxforddictionaries.com/definition.pdf

Razzaque, M.A. \& Sheng, C.C., 1998, 'Outsourcing of logistics function - A literature survey', International journal of Physical Distribution \& Logistics Management 28(2), 89-107. https://doi.org/10.1108/09600039810221667

Rushton, A., Croucher, P. \& Baker, P., 2016, The handbook of logistics and distribution management - Understanding the supply chain, 6th edn., Kogan Page, London.

Sahay, B.S. \& Sahay, B.S. (eds.)., 2006, 3PL, 4PL and reverse logistics: Part two, Emerald Publishing Limited, ProQuest Ebook Central, viewed, 17 June 2017, from https://0 ebookcentral-proquest-com.ujlink.uj.ac.za/lib/ujlinkebooks/detail. action?doclD=285506

Soodyall, S.B. \& Singh, A.M., 2013, Outsourcing the logistics function - a theoretical overview, viewed 08 April 2017, from www.academia.edu
Statistics South Africa, 2017, Consumer Price Index, viewed 08 April 2017, from http:// www.statssa.gov.za/publications/P0141/CPIHistory.pdf.

Stock, J.R. \& Lambert, D.M., 2001, Strategic logistics management, International Edition, 4th edn., McGraw-Hill, Boston, MA.

Tlaty, M. \& Moutmihi, M., 2015, 'From the logistics function to the logistics service: A literature review', Global Journal of Management And Business Research 15(6), viewed 12 August 2021, from https://journalofbusiness.org/index.php/GJMBR/ article/view/1631.

Van Weele, AJ., 2010, Purchasing and supply chain management: Analysis, strategy, planning and practice, 5th edn., Cengage Learning, Hampshire.

Wallenberg, C.M., 2009, 'Innovation in logistics outsourcing relationships: Proactive improvement by logistics service providers as a driver of customer loyalty', Journal of Supply Chain Management 45(2),75-93. https://doi.org/10.1111/ j.1745-493X.2009.03164.X

Waugh, B. \& Luke, R., 2011, 'Logistics outsourcing by manufacturers in SA', The Journa of Transport and Supply Chain Management 5(1), 337-360. https://doi. org/10.4102/jtscm.v5i1.81

Wentworth, F., 2003, 'Outsourcing services: The case against', Logistics \& Transport Focus 5(2), 42

Yin, R.K., 2014, Case study research design and methods, 5th edn., Sage, Thousand Oaks, CA. 